\title{
RESENHA CRÍTICA DO LIVRO: O IMPÉRIO DO CAPITAL
}

\section{RESEÑA CRÍTICA DEL LIBRO: EL IMPERIO DE LA CAPITAL}

\section{CRITICAL BOOK REVIEW: THE CAPITAL EMPIRE}

DOI: http://dx.doi.org/10.9771/gmed.v12i1.37276

Elson Moura Dias Junior ${ }^{1}$

Em tempos - atravessados pela conjunção de uma crise do capital e uma crise pandêmica/sanitária - onde as assim chamadas disputas interimperialistas não respeitam nenhum tipo de trégua para recolher seus(suas) mortos(as) e cuidar de seus(suas) feridos(as), pelo contrário, aproveitam a conjuntura para acirra-las, abre-se mais um campo de possibilidades para aprofundamento do entendimento sobre a característica desta forma de imperialismo, a do capital. Especialmente se pensarmos na função dos Estados nacionais frente a um capitalismo global. É o que nos oferece Ellen Wood em sua obra "o Império do capital”2.

Nesta obra que agora resenhamos, originalmente publicada em 2003, Wood responde à questão do que pode significar este imperialismo na ausência de conquista colonial e dominação imperial direta ${ }^{3}$. Para tal, investiga esta forma atual comparando-a aos precedentes históricos: desde a Roma antiga, passando pela Europa medieval, o mundo árabe maometano, as conquistas espanholas e o império comercial holandês. Vai além e investiga o nascimento do imperialismo capitalista através da dominação inglesa na Irlanda e o seu consequente desenvolvimento através do Império Britânico na América e na Índia ${ }^{4}$. Assim, acompanharemos a autora na ênfase que esta dá à exposição dos seus estudos sobre a posição de supremacia global alcançada pelos Estados Unidos.

$\mathrm{Na}$ Introdução da obra nos oferece uma síntese sobre as características deste "novo" imperialismo:

O que torna a dominação de classe, ou o imperialismo, especificamente capitalista é a predominância da coerção econômica, que se distingue da coerção "extraeconômica" - política, militar ou judicial - direta. Ainda assim, isso não quer dizer, de forma alguma, que o imperialismo capitalista possa abrir mão da força extraeconômica. Primeiro, o capitalismo certamente não exclui formas mais tradicionais de colonização coercitiva. Pelo contrário, sua história, desnecessário dizer, é uma história sangrenta e muito longa de conquista e opressão colonial; e, de qualquer maneira, o desenvolvimento de imperativos econômicos suficientemente fortes para substituir formas mais antigas de dominação direta se deu em um período muito longo, só chegando à plena realização no século XX. Contudo, mais particularmente, mesmo nessa forma mais madura o imperialismo capitalismo exige apoio extraeconômico. A força 

econômica em si. (WOOD, 2014, p. 17).

Novas (economia) e velhas (política, direito e forças armadas) predominâncias interagindo e, assim, criando uma nova síntese, um império capitalista. Não à toa, a autora faz uma afirmação que poderia ser julgada contraditória para os(as) que enxergam na relação entre Estado nacional e capitalismo global uma relação de interesses completamente antagônicos. Ao contrário, Wood afirma ser o Estado hoje ainda mais essencial para o capital.

O capítulo 1 é dedicado a explicar justamente esta relação entre a "economia capitalista" global e o "Estado territorial" a partir do destacamento do poder econômico em relação à força extraeconômica; o que, por sua vez, delineia a relação geral entre o poder econômico e o poder político no capitalismo. O faz inicialmente destacando que estas relações têm como base aquilo que com nossas palavras identificaremos como sendo uma subsunção real ao mercado capitalista. Para a autora, produtores e apropriadores dependem diretamente do mercado para o atendimento de suas necessidades básicas. Assim, estão todos(as) sujeitos(as) aos imperativos da concorrência, acumulação e produtividade.

Uma consequência importante desta separação é o alcance da hegemonia econômica do capital, não mais limitado pela dominação política direta. As leis da economia modelam todos os aspectos da vida, não só a produção e circulação de bens, mas, também, a distribuição de recursos, a disposição do trabalho e a própria organização do tempo.

O que não significa, como já alertamos, a dissolução do poder político do Estado. Para Wood, os capitalistas dependem, em última análise, do poder coercitivo deste aparelho como forma de manter os seus poderes econômicos e o domínio da propriedade, para manter a ordem social e as condições favoráveis à acumulação ${ }^{5}$. O Estado nacional brasileiro e seus governos dos últimos anos, aliás, nos oferecem um conjunto vasto de exemplos desta atuação que beneficia, em última instância, os interesses do mercado. "Mas existe uma divisão mais ou menos clara de trabalho entre os poderes exploradores do capitalista e os poderes coercitivos do Estado" (WOOD, 2014, p. 22).

O desafio é identificar nesta relação onde se localiza o centro do poder capitalista. "Ele parece estar em toda parte e em lugar algum" (WOOD, 2014, p. 24). Se não se encontra em posse de uma expressão singular de Estado-nação, tampouco encontramos alguma organização multinacional capaz de exercer exclusivamente a função de órgão coercitivo político (jurídico e militar) do capital global. Para a autora, em síntese, "A forma política da globalização é, mais uma vez, não um Estado global, mas um sistema global de múltiplos Estados locais, estruturados numa relação complexa de dominação e subordinação" (WOOD, 2014, p. 27-28). Este, um movimento necessário para os objetivos capitalistas ${ }^{6}$.

Os capítulos 2 e 3 são dedicados à caracterização dos impérios não capitalistas, logo, dedicados a caracterizar o "império da propriedade" e o "império do comércio".

Sobre o "império da propriedade", ao citar os exemplos de Roma, China e da América Hispânica, Wood explica parte importante da coerção extraeconômica. Com a exposição de 

a importância da expansão através da colonização (inclusive além-mar), da posse da terra, do poder militar ${ }^{7}$, da centralização do poder ou da "descentralização" através de aristocracias de proprietários de terra, valorização dos laços culturais, ideológicos e do direito universalistas ${ }^{8}$ e de uma igreja universal ${ }^{9}$.

Sobre o império do comércio e, de novo, citando e explicando a partir dos exemplos do império Árabe Mulçumano, Veneziano e a República Holandesa, a autora explica um processo de transição que vai dos impérios baseados no domínio territorial, para os impérios baseados no domínio comercial, mas ainda não suficientemente desenvolvidos à ponto de abrir mão da predominância da coerção extraeconômica. O que implica, de um lado, a dominação territorial, de outro, mais o controle do comércio do que o trabalho forçado.

O controle do comércio implica necessariamente a apropriação do lucro. Mas, não através da exploração tipicamente capitalista:

O lucro comercial não capitalista, por comparação, dependia da separação dos mercados, de comprar barato em um e vender caro em outro; e a riqueza mercantil verdadeiramente grande era resultado das vantagens de negociar em mercados separados que estavam muito distantes uns dos outros, com a ajuda do poder militar. (WOOD, 2014, p. 51) ${ }^{10}$.

Ainda neste capítulo explica a ideologia que sustenta o imperialismo comercial. Para tal, usa o exemplo do Holandês Hugo Grócio (1583-1645). Sua formulação, assim como a de outros teóricos do século XVII, apresenta uma concepção do estado da natureza, onde os indivíduos possuem direitos naturais anteriores à sociedade civil e dela independentes.

No capítulo 4, Wood explica a constituição de uma nova espécie de império. A Inglaterra é o centro da análise. E embora, tal qual os grandes impérios europeus, tenha se utilizado da coerção extraeconômica, especialmente a colonização, foi este país quem, à sua época, melhor respondeu aos imperativos do capitalismo.

O processo de colonização da Irlanda é, aliás, uma expressão singular bastante representativa. O objetivo da conquista militar estava submetido ao objetivo de transformar a sociedade irlandesa, usando colonos ingleses e escoceses, com o fim de tornar a terra produtiva. Praticamente isso significa a erradicação do "sistema irlandês de propriedade", substituído por "uma economia comercial movida pelos imperativos do mercado" (WOOD, 2014, p. 69). A produtividade e lucratividade baseada nos padrões da agricultura comercial inglesa era o parâmetro para a expropriação das terras irlandesas, ainda que estivessem ocupadas.

Esta nova relação, portanto, exigiu um cálculo do valor da terra não mais simplesmente determinado por trocas comerciais mais ou menos acidentais. A teoria econômica política clássica formula a explicação que até hoje reconhecemos como sendo o centro teoria do valor: a quantidade de trabalho humano necessário para a produção passa a ser o padrão comum de medida entre duas mercadorias completamente distintas. 
No capítulo 5, Wood nos apresenta o movimento de transplantação dos imperativos econômicos da Inglaterra para seus territórios imperiais, o que, segundo a autora, distingui o imperialismo inglês de outros projetos coloniais. Isso implica na consideração do direito à propriedade sendo condicionado ao uso e a transformação. Cita Locke e sua formulação de que "O trabalho estabelece um direito de propriedade porque é o trabalho que 'põe a diferença de valor em tudo’. E o valor em questão não é o valor 'intrínseco', mas valor de troca”. (WOOD, 2014, p. 80). Mas, para que este direito à propriedade não fosse generalizado a todos homens e mulheres, em tempos de defesa de liberdades e igualdades naturais, a ideologia operou no sentido de colocar negros(as) fora deste universo normal da liberdade e igualdade. Assim garantiu-se uma subordinação permanente ${ }^{11}$.

No longo e rico capítulo 6, Wood expõe o movimento da internacionalização dos imperativos capitalistas. Movimento impulsionado pelas disputas interimperialistas e interestatais. A assim chamada "Era clássica do Imperialismo" (WOOD, 2014, p. 97) pode ser caracterizada por um capitalismo bem avançado em várias partes do mundo, mas ainda não enquanto um sistema econômico verdadeiramente global12.

Disputas que encontram sua máxima expressão com a guerra mundial, de onde países imperialistas saiam em frangalhos, mas já apontavam para os Estados Unidos enquanto candidato mais próximo de se tornar o primeiro império verdadeiramente econômico, “[...] o que não se pode afirmar ter ocorrido antes do final da Segunda Guerra Mundial”. (WOOD, 2014, p. 99).

A Guerra Fria marca uma transição entre os interesses de expansão imperialista e rivalidades interimperialistas para o objetivo genérico de "policiar o mundo no interesse do capital (norte-americano)" (WOOD, 2014, p. 100). Isso abre um precedente importante para o estabelecimento dos "Estados-nação": "O novo imperialismo que viria surgir do naufrágio do anterior não seria uma relação entre senhores imperiais e súditos coloniais, mas uma interação complexa entre Estados mais ou menos soberanos" (WOOD, 2014, p. 100).

Período importante que marca o domínio econômico através do endividamento estatal como principal instrumento do novo imperialismo. E de pensar nas funções (e nos limites) das organizações globais. O exemplo da Organização das Nações Unidas (ONU) é representativo ${ }^{13}$. A globalização é apresentada enquanto um mecanismo de internacionalização dos capitais, em seus movimentos rápidos, livres e de mais predatória especulação financeira por todo o globo. Atuando através, especialmente, do FMI e do Banco Mundial, o poder imperial exigiu ajustes estruturais e uma variedade de medidas de tornar as economias ainda mais vulneráveis às pressões do capital global (sob o comando dos Estados Unidos).

O que não significou, como já adiantamos, uma dissolução da importância dos Estados locais. Pelo contrário, o "Estado está no coração do novo sistema global" (WOOD, 2014, p. 106). Atua como garantidor administrativo e coercitivo da nova ordem social, criando e mantendo 
condições de acumulação de capital. O que vai causar a impressão de um declínio do Estado tem mais a ver com a retirada deste de suas funções de bem-estar social e melhoria social ${ }^{14}$.

Mas, já preparando o próximo capítulo, a autora cita que nas condições acima caracterizadas é inevitável que "administrar um sistema como esse exige, em última instância um único poder militar esmagador, capaz de manter todos os outros na linha” (WOOD, 2014, p. 108). Para nós, uma síntese perfeita entre a necessidade de Estados-nação para garantir os imperativos capitalistas globais, tendo uma única força a função de acompanhamento e policiamento destes imperativos.

Os Estados Unidos, como já adiantamos, cumpre este papel. Aproveitando a suspensão das rivalidades geopolíticas e militares diretas, este país assume a posição de maior poder militar que o mundo já viu. Para tal, responde por, no mínimo, 40\% do orçamento de guerra do mundo. Um poder militar, diferente dos precedentes históricos, não necessário para conquistas de territórios nem derrotar rivais. $E$ justamente por não ter um objetivo claro e finito que se produz uma capacidade militar desproporcional de alcance global. Justificando essa existência, as estratégias definidas como "guerra sem fim”, "guerra contra o terrorismo", "Operação Justiça Infinita”, "guerra justa”, “guerra humanitária” e “intervenção defensiva” (WOOD, 2014, p. 110-114), garantem a perenidade do movimento de guerra: "Então é isso: guerra total e infinita - não necessariamente guerra contínua, mas uma guerra indefinida em termos de duração, objetivos, meios e alcance espacial".

Em síntese temos um tipo de imperialismo dependente de uma hegemonia econômica de longo alcance, o que lhe possibilita uma expansão para além das fronteiras dos Estados territoriais. Isso não significou a dissolução da importância dos Estados-nação. Esses ganham ainda mais centralidade enquanto sistema político, jurídico e militar de garantia dos interesses imperialistas. Esse movimento de expansão global é acompanhado de perto por um poderio econômico e militar nunca antes visto e, por isso, garantidor da ordem. Este o papel dos Estados Unidos nesta fase imperialista.

\section{Referência}

WOOD, Ellen Meiksins. O império do capital. Tradução: Paulo Cezar Castanheiras. 1. ed. São Paulo: Boitempo, 2014.

\footnotetext{
Notas

${ }^{1}$ Professor da Universidade Estadual de Feira de Santana - UEFS. Doutorando no PPGE FACED UFBA. Membro do Grupo de Estudos e Pesquisas Marxismo e Políticas de Trabalho e Educação - M.T.E. http://dgp.cnpq.br/dgp/espelhogrupo/195099 CV: http://lattes.cnpq.br/8655211408049083 Orcid: https://orcid.org/0000-0003-3197-7749 E-mail: emdjunior@uefs.br

2 Nascida em 1942, a autora foi durante anos professora de Ciência Política da Universidade de York. Além desta obra, traduzida ao português, temos "Democracia contra capitalismo", "A origem do capitalismo" e "Em defesa da história". Ainda sem tradução: "The Retreat from Class", "Peasant-Citizen and Slave" e "The Pristine Culture of Capitalism".
} 
$3 \mathrm{O}$ que aqui apresentamos enquanto síntese, na obra aparece através de sete capítulos (além da Introdução) - 1- O deslocamento do poder econômico, 2- O império da propriedade, 3- O império do comércio, 4- Uma nova espécie de império, 5- A expansão ultramarina dos impérios econômicos, 6- A internacionalização dos imperativos capitalistas, 7 "Imperialismo excedente", guerra sem fim - mais um tipo de posfácio onde a autora oferece "Resposta aos críticos".

${ }^{4}$ Mas, faz um alerta: "Este livro não é uma história do imperialismo. Apesar de grande parte de sua argumentação ser histórica, o objetivo de suas excursões à história do império é colocar em relevo a especificidade do imperialismo capitalista, observando-o contra o pano de fundo contrastante de outras formas imperiais" (WOOD, 2014, p. 18).

5 "O Estado-nação ofereceu isso por meio de uma elaborada estrutura legal e institucional, apoiada pela força coercitiva, para sustentar as relações de propriedade do capitalismo, seu complexo aparelho contratual e suas intricadas transações financeiras". (WOOD, 2014, p. 26).

${ }^{6}$ De um lado, a expansão do capital é possível exatamente porque ele é capaz de se descolar do poder extraeconômico de maneira inacessível a qualquer outra forma social; e. de outro, esse mesmo deslocamento torna tanto possível quanto necessário que a hegemonia econômica do capital seja apoiada pelos Estados territoriais. (WOOD, 2014, p. 31).

${ }^{7}$ Que, diferente do uso das forças armadas pelos impérios capitalistas, aparece sem mistério.

8 "A fragmentação e o particularismo do império também causaram uma valorização dos laços culturais e das ideologias universalistas capazes de ajudar a juntar os fragmentos" (WOOD, 2014, p. 38).

9 "Para desempenhar o papel imperial, a religião cristã teve de se submeter a uma transformação significativa. Teve de se transformar de uma seita radical judaica, que se opunha à autoridade temporal do império, numa doutrina submissa à e até incentivadora da - obediência imperial". (WOOD, 2014, p. 38).

10 "Num mercado não capitalista, em que o comércio não era movido pela competição de preços nem pela produção competitiva, mas pelo comando extraeconômico direto dos mercados e do sucesso na rivalidade extraeconômica, particularmente a militar, o comércio era um jogo de soma zero, em que o ganho de uma cidade era a perda da outra. Isso significa que cidades rivais e suas elites mercantis tinham de ser derrotadas, ou ao menos enfraquecidas" (WOOD, 2014, p. 54).

11 “[...] o que foi conseguido pela construção de categorias raciais mais rígidas que as existentes em qualquer época anterior - sob a forma de concepções pseudocientíficas de raça ou ideologia patriarcais em que os escravos africanos eram eternas crianças" (WOOD, 2014, p. 86).

12 " $\mathrm{Na}$ verdade, o capitalismo depende para sua sobrevivência não somente da existência dessas formações não capitalistas, mas de instrumentos essencialmente pré-capitalistas de força 'extraeconômica': coerção militar e geopolítica, tradicionais rivalidades entre Estados, guerras coloniais e domínio territorial” (WOOD, 2014, p. 98-99).

13 "Criada para ter pouco efeito sobre a economia global, a ONU teria o papel de manter um simulacro de ordem política num sistema de Estados múltiplos, sendo sua própria existência um desincentivo a formas de organização internacional menos adequadas às potências dominantes" (WOOD, 2014, p. 102).

14 "O próprio fato de a 'globalização' ter estendido os poderes puramente econômicos muito além do alcance de qualquer Estado nacional significa que o capital global exige muitos Estados-nação para executar as funções administrativas e coercitivas que sustentam o sistema de propriedade e oferecem o tipo de regularidade e previsibilidades diárias, bem como a ordem legal de que o capitalismo necessita mais que qualquer outra forma social" (WOOD, 2014, p. 107).

Recebido em: 11.06 .2020

Aprovado em: 24.07.2020 